\title{
Management of post-cholecystectomy biliary fistula according to type of cholecystectomy
}

Authors

Institution
Ahmad M. Sultan, Ayman M. Elnakeeb, Mohamed M. Elshobary, Ahmed A. El-Geidi, Tarek Salah, Ehab A. El-hanafy, Ehab Atif, Emad Hamdy, Gamal K. Elebiedy

Gastro-enterology Surgical Center, Surgery Department, Mansoura University, Mansoura, Egypt submitted 24. April 2014 accepted after revision 8. September 2014

\section{Bibliography}

Dol http://dx.doi.org/ 10.1055/s-0034-1390747

Published online: 24.10 .2014

Endoscopy International Open 2015; 03: E91-E98

(c) Georg Thieme Verlag KG Stuttgart . New York

E-ISSN 2196-9736

\section{Corresponding author}

Ahmad Mohammad Sultan,

MD

Gastro-enterology Surgical

Center

Mansoura University

Gehan Street

Mansoura

Egypt

Fax: 002050223686

dr_ahmadsultan@hotmail.com
Background and study aims: A study was undertaken to describe the management of post-cholecystectomy biliary fistula according to the type of cholecystectomy.

Patients and methods: A retrospective analysis of 111 patients was undertaken. They were divided into open cholecystectomy (OC) and laparoscopic cholecystectomy (LC) groups.

Results: Of the 111 patients, 38 (34.2\%) underwent LC and 73 (65.8\%) underwent OC. Endoscopic retrograde cholangiopancreatography (ERCP) diagnosed major bile duct injury (BDI) in 27 patients $(38.6 \%)$ in the OC group and in 3 patients $(7.9 \%)$ in the LC group $(P=0.001)$. Endoscopic management was not feasible in 15 patients (13.5\%) because of failed cannulation $(n=3)$ or complete ligation of

\section{Introduction}

$\nabla$

Despite the fact that laparoscopic cholecystectomy (LC) is the gold standard treatment for symptomatic gallbladder disease, open cholecystectomy $(\mathrm{OC})$ is the ultimate approach when the laparoscopic route fails. Furthermore, OC is still widely performed in many parts of the world. The lack of necessary laparoscopic equipment in government hospitals and the fact that private practices handle a large share of the medical services are two important reasons for the popularity of OC in countries like Egypt [1].

Several classifications of bile duct injury (BDI) exist that address different types of injuries, management modalities, prognosis, and associated injuries [2]. Biliary leakage or fistula is one of the common presentations of BDI [3] and is included in many of the most widely used classifications of BDI [4-6].

Endoscopic modalities, including endoscopic sphincterotomy, stenting, and the placement of nasobiliary drains, have replaced surgery as a first-line approach to the management of minor the common bile duct $(\mathrm{n}=12)$. Endoscopic therapy stopped leakage in 35 patients (92.1\%) and 58 patients (82.9\%) following LC and OC, respectively, after the exclusion of 3 patients in whom cannulation failed ( $P=0$ 0.150). Major BDI was more commonly detected after OC $(P<0.001)$. Leakage was controlled endoscopically in 77 patients $(98.7 \%)$ with minor BDI and in 16 patients (53.3\%) with major BDI $(P<0.001)$.

Conclusions: Major BDI is more common in patients presenting with bile leakage after OC. ERCP is the first-choice treatment for minor BDI. Surgery plays an important role in major BDI. Magnetic resonance cholangiopancreatogrphy (MRCP) should be used before ERCP in patients with bile leakage following OC or converted LC.

BDI [7-9], whereas surgical reconstruction is the ideal treatment for major BDI [9-11].

In this article, we aim to share our experience of patients referred to our endoscopy unit for the management of post-cholecystectomy biliary leakage, with special emphasis on the incidence of major BDI following open or laparoscopic procedures and the role of magnetic resonance cholangiopancreatography (MRCP) before endoscopic retrograde cholangiopancreatography (ERCP).

\section{Patients and methods}

$\nabla$

Between May 1994 and May 2011, 111 patients with the diagnosis of post-cholecystectomy biliary leakage or biliary fistula were identified in the computerized database of the ERCP unit of the Gastro-enterology Surgical Center, Mansoura University, Mansoura, Egypt. Our unit is the referral unit for the Egyptian Delta area, which serves more than 5 million persons. We treat patients referred from private practices, government district 


\begin{tabular}{|c|c|c|c|c|}
\hline Parameter & $\begin{array}{l}\text { LC } \\
(n=38)\end{array}$ & $\begin{array}{l}\text { OC } \\
(n=73)\end{array}$ & $\begin{array}{l}\text { Total } \\
(n=111)\end{array}$ & $P$ value \\
\hline \multicolumn{5}{|l|}{ Sex } \\
\hline Male & $12(32 \%)$ & $37(51 \%)$ & $49(44 \%)$ & \multirow{2}{*}{0.07} \\
\hline Female & $26(68 \%)$ & $36(49 \%)$ & $62(56 \%)$ & \\
\hline \multicolumn{5}{|l|}{ Age, y } \\
\hline Mean (SD) & $42.6(14)$ & $47.5(12)$ & 46 & \multirow{2}{*}{0.136} \\
\hline Median (range) & $41(16-65)$ & $48(17-80)$ & $(16-80)$ & \\
\hline \multicolumn{5}{|l|}{ Bile leak } \\
\hline Surgical drain & $26(68 \%)$ & $38(52 \%)$ & $64(58 \%)$ & \multirow{4}{*}{0.085} \\
\hline US-guided tube drain & $12(32 \%)$ & $22(30 \%)$ & $34(30 \%)$ & \\
\hline Drain site & 0 & $4(6 \%)$ & $4(4 \%)$ & \\
\hline Wound & 0 & $9(12 \%)$ & $9(8 \%)$ & \\
\hline \multicolumn{5}{|l|}{ Referral } \\
\hline Private & $15(40 \%)$ & $55(75 \%)$ & $70(63 \%)$ & \multirow{3}{*}{$<0.001$} \\
\hline Governmental hospital & $8(21 \%)$ & $16(22 \%)$ & $24(22 \%)$ & \\
\hline Tertiary referral center & $15(39 \%)$ & $2(3 \%)$ & $17(15 \%)$ & \\
\hline \multicolumn{5}{|l|}{ Symptoms } \\
\hline Pain & $34(90 \%)$ & $58(80 \%)$ & $92(83 \%)$ & 0.143 \\
\hline Jaundice & $11(29 \%)$ & $42(58 \%)$ & $53(48 \%)$ & 0.005 \\
\hline Fever & $17(45 \%)$ & $30(41 \%)$ & $47(42 \%)$ & 0.840 \\
\hline Abdominal distension & $8(21 \%)$ & $21(29 \%)$ & $29(26 \%)$ & 0.496 \\
\hline Total & 38 & 73 & 111 & \\
\hline
\end{tabular}

Table 1 Epidemiology and symptoms of the study population.

LC, laparoscopy cholecystectomy; OC, open cholecystectomy; US, ultrasound.

hospitals, and university hospitals, as well as patients who undergo LC at our center

The diagnosis of biliary leak was based on the presence of bile in abdominal drains or abdominal collections, or bile exiting through abdominal wounds. The medical records and follow-up visits of these patients were reviewed. The study population was divided into OC and LC groups. Patients who had undergone OC and T-tube insertion were included in the OC group.

We classified BDI as major or minor based on the classification of Bergman et al. [5]. Major BDI was defined as ligation or stricture of the common bile duct (CBD), common hepatic duct (CHD), or right hepatic duct (RHD). Cystic duct and cholecystohepatic duct leaks were classified as minor BDI. Bile leakage around a T-tube with no associated strictures was considered a minor BDI.

All patients were discharged after cessation of the bile leak or progressive reduction of the daily effluent. Patients were followed up in the outpatient clinic for 8 to 12 weeks or until definitive treatment of the cause of the leakage. Plain abdominal X-ray studies were ordered for patients who underwent stent placement before another ERCP was scheduled for stent removal and follow-up cholangiography. ERCP was not considered for patients with stents that had migrated and no symptoms.

The primary outcome was the incidence of major BDI after OC or LC. Secondary outcomes were the success of ERCP in resolving bile leak (initial success rate) and treating its cause, in addition to the adverse effects of ERCP and subsequent procedures.

\section{Definitions}

\section{$\nabla$}

Pre-ERCP management includes all procedures performed before ERCP, whether before or after admission to our hospital. Primary management is defined as management during the initial ERCP procedure. Secondary management is defined as all therapeutic procedures used to control persistent biliary leakage following the primary procedure until resolution of the leakage. Definitive management is defined as the therapeutic procedures undertak- en to definitively treat the underlying cause of biliary leakage if it was not corrected previously (e.g., missed stones or biliary strictures).

\section{Statistical analysis \\ $\nabla$}

Continuous variables are presented as median with range. Categorical variables are presented as proportions. Continuous variables were compared over the LC group and OC group with the two-tailed Mann-Whitney $U$ test, whereas categorical variables were compared with the chi-squared test or Fischer's exact test if applicable. A $P$ value of less than 0.05 was considered statistically significant. All analyses were performed with SPSS 17.0 for Windows (SPSS, Chicago, Illinois).

\section{Results \\ $\nabla$}

During the study period, more than 9000 ERCP procedures were performed in our unit, including procedures in 111 patients who underwent ERCP for the management of post-cholecystectomy biliary leakage. The patients' demographics and symptoms are shown in Table 1. The OC group includes 2 patients whose procedure was converted from an LC.

\section{Pre-ERCP management $(\bullet$ Table 2 )}

The cholecystectomy-ERCP interval was significantly shorter in the LC group (median, 5 days; range, $1-45$ ) than in the OC group (median, 15 days; range, $2-100 ; P<0.001$ ). Ultrasound-guided tube drain placement was used in 39 patients (35\%), with no significant difference between the groups. Surgical exploration and drainage with or without T-tube placement was done in 2 patients $(5 \%)$ in the LC group and 10 patients $(13.7 \%)$ in the OC group $(P=<0.001)$ 


\begin{tabular}{|c|c|c|c|c|}
\hline & $\begin{array}{l}\text { LC } \\
(n=38)\end{array}$ & $\begin{array}{l}\text { OC } \\
(n=73)\end{array}$ & $\begin{array}{l}\text { Total } \\
(n=111)\end{array}$ & $P$ value \\
\hline \multicolumn{5}{|l|}{ Pre-ERCP imaging } \\
\hline Collection & $18(47 \%)$ & $43(59 \%)$ & $61(55 \%)$ & 0.169 \\
\hline Missed stones & $3(8 \%)$ & $7(10 \%)$ & $10(9 \%)$ & 0.525 \\
\hline \multicolumn{5}{|l|}{ Pre-ERCP management } \\
\hline US-guided tube drain & $14(37 \%)$ & $25(34 \%)$ & $39(35 \%)$ & 0.458 \\
\hline Exploration and drainage & $2(5 \%)$ & $8(11 \%)$ & $10(9 \%)$ & \multirow{2}{*}{$<0.001$} \\
\hline Exploration and T-tube & 0 & $2(3 \%)$ & $2(2 \%)$ & \\
\hline \multicolumn{5}{|l|}{ Interval to ERCP, days } \\
\hline Mean (SD) & $8.3 \pm 1.5$ & $28.5 \pm 4$ & $18.9 \pm 2.2$ & \multirow[t]{2}{*}{$<0.001$} \\
\hline Median (range) & $5(1-45)$ & $15(2-100)$ & $9(1-00)$ & \\
\hline Diagnostic ERCP success rate & $38(100 \%)$ & $70(96 \%)$ & $108(97 \%)$ & 0.550 \\
\hline
\end{tabular}

Table 2 Pre-ERCP management, procedure-ERCP interval, and diagnostic ERCP success rate.

ERCP, endoscopic retrograde cholangiopancreatography; LC, laparoscopy cholecystectomy; OC, open cholecystectomy; US, ultrasound.

\begin{tabular}{|c|c|c|c|c|}
\hline ERCP findings & LC $(n=38)$ & $O C(n=70)$ & Total (108) & $P$ value \\
\hline Major bile duct injury & $3(7.9 \%)$ & $27(38.6 \%)$ & $30(27.8 \%)$ & $0.001^{1}$ \\
\hline Ligated CHD & $1(2.6 \%)$ & $11(15.1 \%)$ & $12(11.1 \%)$ & \\
\hline CHD stricture & $1(2.6 \%)$ & $14(19.2 \%)$ & $15(13.8 \%)$ & \\
\hline RHD injury & $1(2.6 \%)$ & $2(2.7 \%)$ & $3(2.7 \%)$ & \\
\hline Minor bile duct injury & $35(92.1 \%)$ & $43(61.4 \%)$ & $78(72.2 \%)$ & \\
\hline Cystic duct leak & $31(81.6 \%)$ & $35(47.9 \%)$ & $66(61.1 \%)$ & \\
\hline Cholecystohepatic duct & $4(10.5 \%)$ & 0 & $4(3.7)$ & \\
\hline Around T-tube & 0 & $7(9.6 \%)$ & $7(6.4)$ & \\
\hline No escape of dye & 0 & $1(1.4 \%)$ & $1(0.9)$ & \\
\hline \multicolumn{5}{|l|}{ Associated findings } \\
\hline Missed stone & $7(18.4 \%)$ & $13(20 \%)$ & $20(18.5 \%)$ & 1.00 \\
\hline Ampullary tumor & 0 & $1(1.4 \%)$ & $1(0.9 \%)$ & \\
\hline Distal CBD stricture & 0 & $1(1.4 \%)$ & $1(0.9 \%)$ & \\
\hline
\end{tabular}

Table 3 ERCP findings in 108 cases, excluding 3 cases in which diagnostic ERCP failed.

ERCP, endoscopic retrograde cholangiopancreatography; LC, laparoscopic cholecystectomy; OC, open cholecystectomy; CHD, common hepatic duct; RHD, right hepatic duct; CBD, common bile duct.

${ }^{1}$ Major bile duct injury versus minor bile duct injury.

\section{ERCP findings and primary management \\ $(\bullet$ Table $3, \odot$ Table 4 and $\odot$ Fig. 1 )}

Diagnostic ERCP was successful in 108 patients (97.3\%) and successfully identified the site of leakage in 107 patients (96.4\%). Cholangiography was not possible in 3 patients in the OC group because of failed cannulation. In 1 patient, there was no extravasation of contrast material; he underwent ERCP 1 month after OC, and a short stent was placed to ensure proper drainage.

ERCP diagnosed major BDI in 27 patients (38.6\%) in the OC group and in 3 patients $(7.9 \%)$ in the LC group $(P=0.001)$. On multivariate analysis, the only significant factor that influenced the occurrence of major BDI was the type of cholecystectomy ( $\bullet$ Table 5). The 12 patients who had a ligated or transected duct with no contrast passing into the proximal biliary tree were referred for definitive surgical reconstruction. CHD strictures ( $\bullet$ Fig.2) were managed by stent placement, with 2 patients requiring dilation of the stricture before stent placement. The source of biliary leakage was the RHD ( $\bullet$ Fig. 3 ) in 3 patients (2.7\%). This was managed by the insertion of a single stent in 2 patients and double stents in 1 patient.

The management of cystic duct leaks ( $\bullet$ Fig.4) is shown in $\bullet$ Table6. Cholecystohepatic duct leaks ( $\bullet$ Fig.5) were identified in 4 patients, with a missed CBD stone in 1 patient. All cholecystohepatic leaks were in the LC group and were managed by stent placement.

Of 10 patients who presented with a bile leak after OC and T-tube placement, 2 patients had a ligated CBD, and they were referred to surgery. The leak was shown to be from the choledochotomy around the T-tube in 7 patients (6.3\%) ( $\bullet$ Fig.6). Management
Table 4 Therapeutic ERCP success rate and initial endoscopic management.

\begin{tabular}{|lc|}
\hline Initial endoscopic treatment & Total (\%) (n=108) \\
\hline Successful (leak resolved) & $93(83.8 \%)$ \\
\hline Stent (single) & $80(72.1 \%)$ \\
\hline Stent (+ stone extraction) & $5(4.5 \%)$ \\
\hline Stent (+dilation) & $2(1.8 \%)$ \\
\hline Stent (double) & $1(0.9 \%)$ \\
\hline ES & $2(1.8 \%)$ \\
\hline ES (+ stone extraction) & $8(7.2 \%)$ \\
\hline Guidewire failed to pass & $12(11.1 \%)$ \\
\hline
\end{tabular}

ERCP, endoscopic retrograde cholangiopancreatography; ES, endoscopic sphincterotomy.

was with stent placement in 4 patients. Cholangiography revealed associated missed stones in the remaining 3 of these $7 \mathrm{pa}-$ tients. They were managed with stent insertion $(n=1)$, stone extraction and stenting $(n=1)$, and endoscopic sphincterotomy with stone extraction $(n=1)$. In the last patient, the source of the leak was the cystic duct in association with a missed stone. The missed stone was extracted, and a stent was placed.

Missed CBD stones were identified in 20 patients (19.4\%). They were associated with a cystic duct leak in 16 cases, leakage around the T-tube in 3 cases, and a cholecystohepatic duct leak in 1 case. Missed stones were managed by endoscopic sphincterotomy and stone extraction in 8 patients $(7.2 \%)$ and by endoscopic sphincterotomy, stone extraction, and stent placement in 5 patients (4.5\%). Placement of a stent, reaching above the stone, was the preferred initial management in 7 patients $(6.3 \%)$, to be followed by stone extraction during stent removal. 


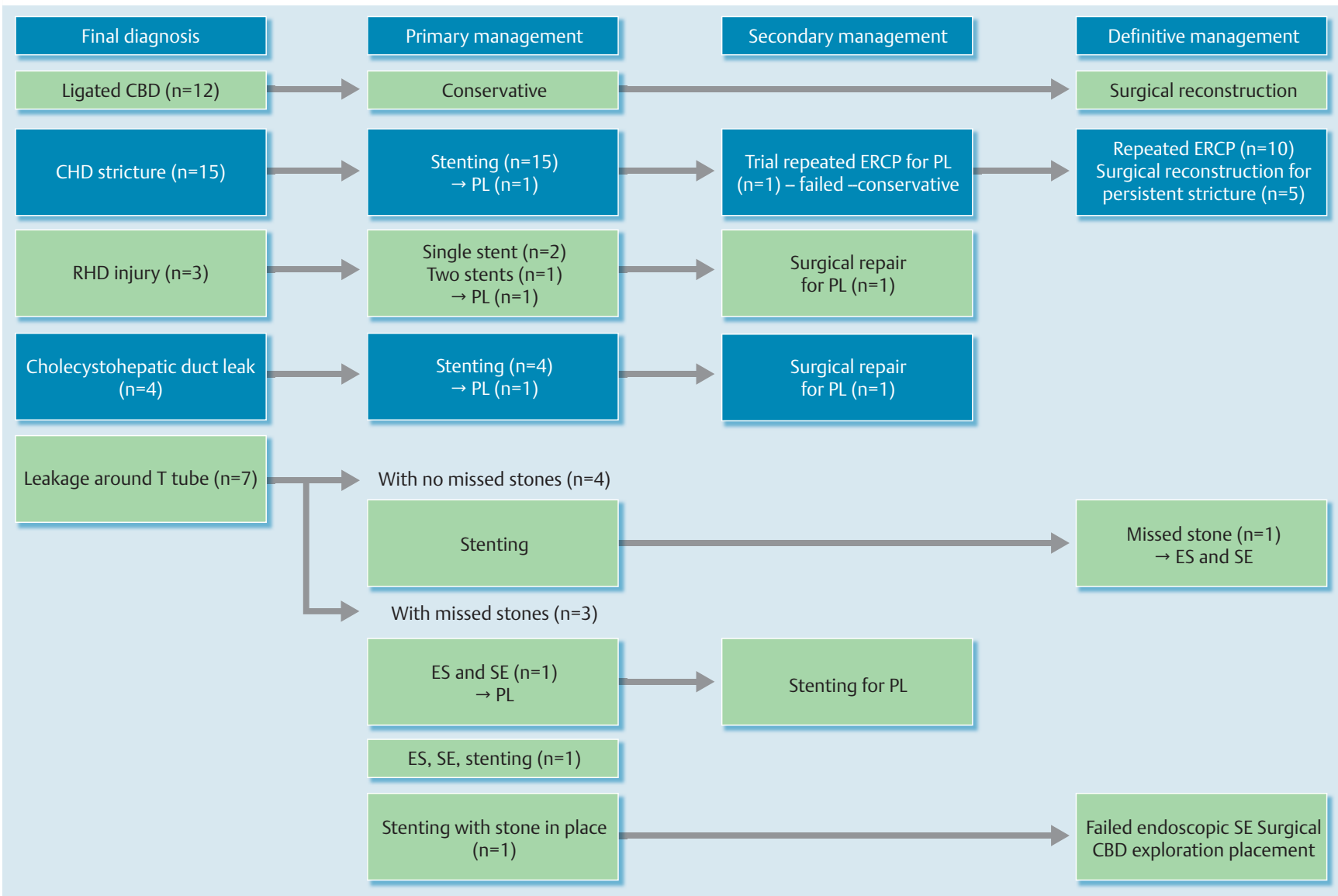

Fig. 1 Primary, secondary, and definitive management of biliary leakage according to diagnosis at endoscopic retrograde cholangiopancreatography, excluding patients with cystic duct leak. CBD, common bile duct; CHD, common hepatic duct; PL, persistent leak; RHD, right hepatic duct; ES, endoscopic sphincterotomy; SE, stone extraction.

\begin{tabular}{|c|c|c|c|c|}
\hline & Minor BDI & Major BDI & $\begin{array}{l}\text { Univariate } \\
P \text { value }\end{array}$ & $\begin{array}{l}\text { Multivari- } \\
\text { ate } P \text { value }\end{array}$ \\
\hline Cholecystectomy-ERCP interval, days & $17 \pm 19.1$ & $34 \pm 46.4$ & 0.005 & 0.136 \\
\hline \multicolumn{5}{|l|}{ Type of cholecystectomy } \\
\hline LC & $35(92.1 \%)$ & $3(7.95 \%)$ & \multirow{2}{*}{0.001} & \multirow{2}{*}{0.008} \\
\hline OC & $43(61.4 \%)$ & $27(38.6 \%)$ & & \\
\hline Age, years & $46.6 \pm 13.3$ & $43.9 \pm 13.2$ & 0.973 & 0.087 \\
\hline \multicolumn{5}{|l|}{ Sex } \\
\hline Male & $35(71.4 \%)$ & $14(28.6 \%)$ & \multirow{2}{*}{0.867} & \multirow{2}{*}{0.803} \\
\hline Female & $43(72.9 \%)$ & $16(27.1 \%)$ & & \\
\hline \multicolumn{5}{|l|}{ Referral } \\
\hline Private & $46(68.7 \%)$ & $21(31.3 \%)$ & \multirow{3}{*}{0.27} & \multirow{3}{*}{0.885} \\
\hline Government hospital & $17(70.8 \%)$ & $7(29.2 \%)$ & & \\
\hline Tertiary referral center & $15(88.2 \%)$ & $2(11.8 \%)$ & & \\
\hline
\end{tabular}

BDI, bile duct injury; ERCP, endoscopic retrograde cholangiopancreatography; LC, laparoscopic cholecystectomy; OC, open cholecystectomy.

\section{Follow-up, adverse effects, secondary and definitive management ( $\odot$ Fig. $1, \odot$ Table 7$)$}

Patients in whom diagnostic ERCP failed

Endoscopic management was not feasible in 15 patients (13.5\%) because of failed cannulation $(n=3)$ or complete ligation of the $\operatorname{CBD}(n=12)$. These patients were referred for surgical reconstruction (definitive management).
Patients with major bile duct injury

Initial endoscopic management with stenting resolved the leakage in 14 of 15 patients (93.4\%). In 1 patient, the leak persisted despite repeated endoscopy and the placement of a stent through a choledochoduodenal fistula, and this patient was referred for surgical reconstruction. The remaining 14 patients underwent an endoscopic treatment regimen. On long-term follow-up, 4 of the 14 patients (28.6\%) were referred for surgical reconstruction because of a poor response to endoscopic treatment. Mild pancreatitis developed in 2 patients (13.4\%). 


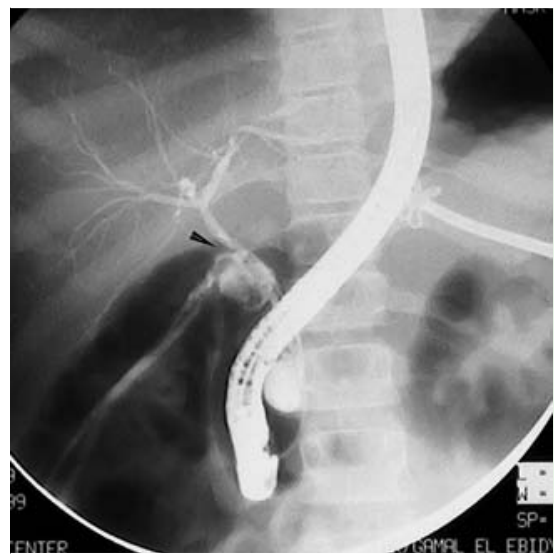

Fig. 2 Endoscopic retrograde cholangiopancreatography showing common hepatic duct injury (major bile duct injury), with contrast escaping from the biliary tree (arrowhead). (Note the ultrasound-guided tube drainage.)

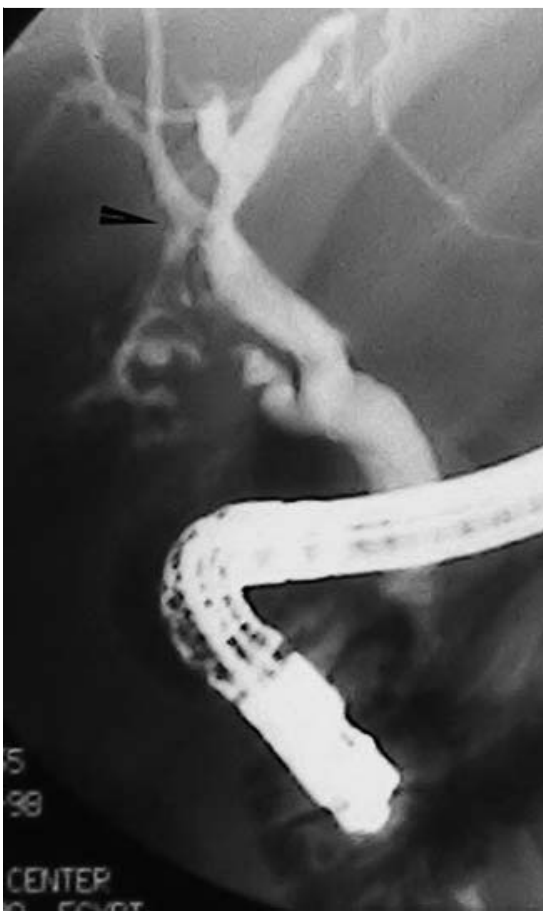

Fig. 3 Endoscopic retrograde cholangiopancreatography showing contrast leakage (arrowhead) associated with right hepatic duct injury (major bile duct injury).

Mild pancreatitis developed in 2 patients with RHD injuries. The third patient's condition did not improve, and operative repair of the injured duct with the stent in place was required. All 3 patients had their stents removed after 2 months, with an intact biliary system on cholangiography.

\section{Patients with minor bile duct injury}

In 1 of 4 patients in whom a cholecystohepatic duct leak was diagnosed, leakage persisted for 5 days after ERCP. This patient underwent exploration and control of the leaking point, and drainage was performed with subsequent resolution of the leak.

Of the 4 patients with an established diagnosis of bile leakage around the T-tube with no missed stones, 2 had their stents removed after 2 months. A missed stone was noticed and extracted during stent removal in the third patient. The leak resolved 4 days after stent insertion in the fourth patient, who was referred for ERCP 28 days after the initial surgery. Sepsis was already irreversible, and he died 18 days after ERCP.

On initial endoscopy, 3 patients had missed stones. On follow-up, the patient who underwent endoscopic sphincterotomy and stone extraction had a persistent leak and required stenting. The leakage stopped after 6 days, and the stent was removed after 2 months. On X-ray films, the stent was found to have migrated in 1

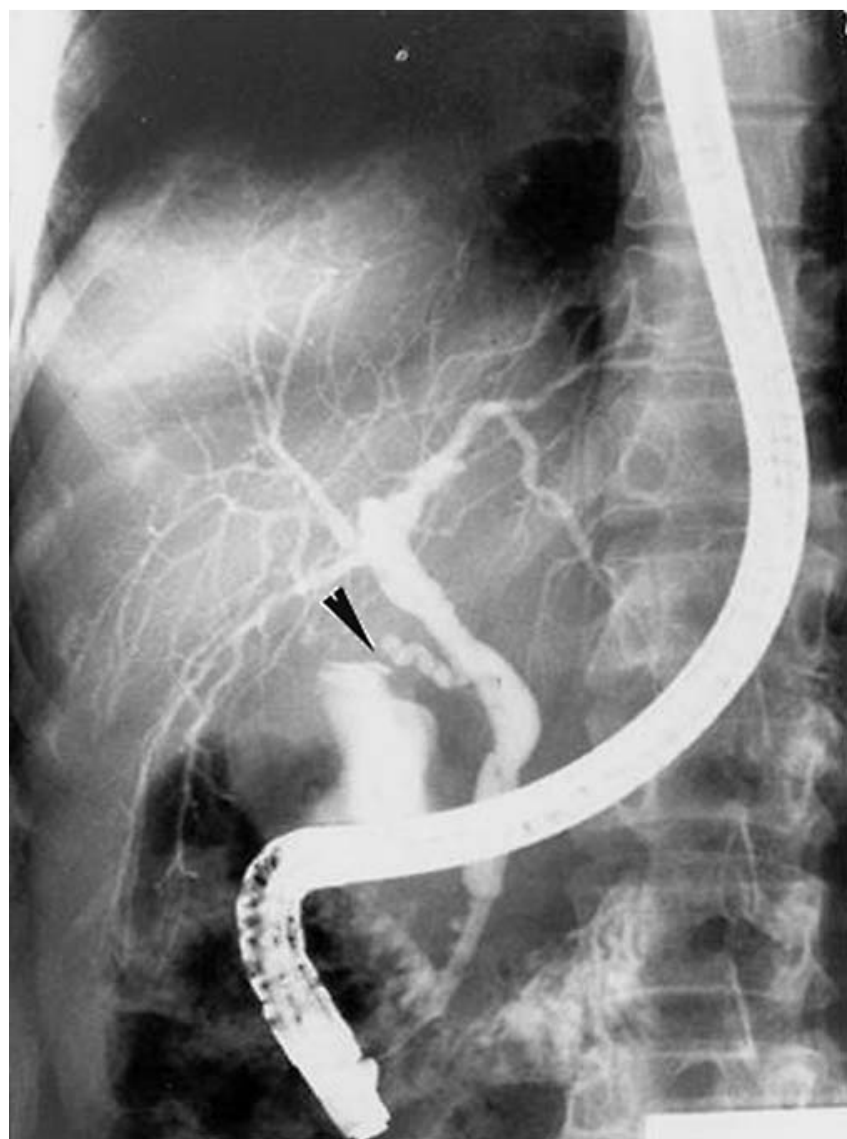

Fig.4 Endoscopic retrograde cholangiopancreatography showing cystic duct leak (arrowhead) (minor bile duct injury).

patient who underwent stone extraction and stent placement. The third patient who underwent stent placement without stone extraction underwent another 2 ERCP procedures in an attempt to extract the stone endoscopically, which failed. He underwent surgery 14 months later and the CBD was explored, with stone extraction and T-tube placement.

\section{Cystic duct leak ( $\odot$ Table 6$)$}

Overall, endoscopic management was successful in all patients with cystic duct leaks. Primary management was successful in 63 patients (95.5\%), with 3 patients requiring a longer stent. The median time required for disappearance of a leak was 3 days (mean, 3.6; range, 2-7). $\odot$ Table 6 shows the different approaches for managing cystic duct leaks, their initial success rates, their adverse effects, including persistent leak, and the number of ERCP procedures needed.

Difference between the open cholecystectomy and laparoscopic cholecystectomy groups/minor and major bile duct injuries

Endoscopic therapy stopped leakage in 35 patients (92.1\%) and 58 patients (82.9\%) following LC and OC, respectively, after the exclusion of 3 patients in whom cannulation failed $(P=0.15)$. Leakage was controlled endoscopically in 77 patients $(98.7 \%)$ with minor BDI and in 16 patients $(53.3 \%)$ with major BDI $(P<$ $0.001)$. Leakage stopped earlier in the group with minor BDI after endoscopic treatment $(P=0.01)$, whereas the numbers of ERCP procedures needed for leak control did not differ significantly between the groups $(P=0.20)$. 
Table 6 Cystic duct leak management and success rate.

\begin{tabular}{|c|c|c|c|c|}
\hline & $\begin{array}{l}\text { Cystic duct leak } \\
(n=16)\end{array}$ & missed stone & & $\begin{array}{l}\text { Cystic duct leak with no missed stone } \\
(n=50)\end{array}$ \\
\hline Primary management & Stent $(n=5)$ & $E S$ and $S E(n=7)$ & $E S$, SE, and stent $(n=4)$ & Stent $(n=50)$ \\
\hline Primary management success rate & $100 \%$ & $5(71.4 \%)$ & $100 \%$ & (49) $98 \%$ \\
\hline Complications & 0 & Persistent leak $(n=2)$ & 0 & $\begin{array}{l}\text { Mild pancreatitis }(n=2) \rightarrow \text { conservative } \\
\text { Persistent leak }(n=1)\end{array}$ \\
\hline Secondary management & & $\begin{array}{l}\text { Stent for persistent } \\
\text { leak }(n=2)\end{array}$ & & Longer stent for persistent leak $(n=1)$ \\
\hline Overall endoscopic success rate & $100 \%$ & & & $100 \%$ \\
\hline Definitive management procedures & $E S$ and $S E(n=5)$ & & & \\
\hline \multicolumn{5}{|l|}{ Number of ERCP procedures } \\
\hline Mean & $2 \pm 0$ & $1.6 \pm 1$ & $1.5 \pm 0.6$ & $1.8 \pm 0.5$ \\
\hline Median (range) & 2 & $1(1-3)$ & $1.5(1-2)$ & $2(1-3)$ \\
\hline \multicolumn{5}{|l|}{ Duration until stoppage of leak, days } \\
\hline Median (range) & $3.6 \pm 0.5$ & $4.3 \pm 1.8$ & $4.3 \pm 1.9$ & $3.4 \pm 1.1$ \\
\hline Mean (SD) & $4(3-4)$ & $5(2-7)$ & $3.5(3-7)$ & $3(2-7)$ \\
\hline
\end{tabular}

ES, endoscopic sphincterotomy; SE, stone extraction; ERCP, endoscopic retrograde cholangiopancreatography.

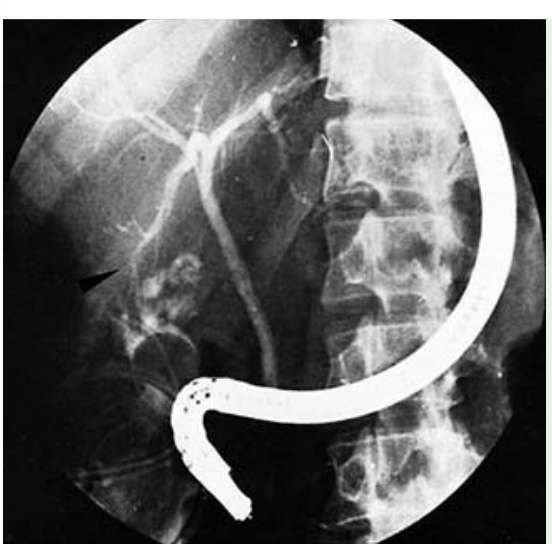

Fig. 5 Endoscopic retrograde cholangiopancreatography showing contrast leakage (arrowhead) from the cholecystohepatic duct (minor bile duct injury).

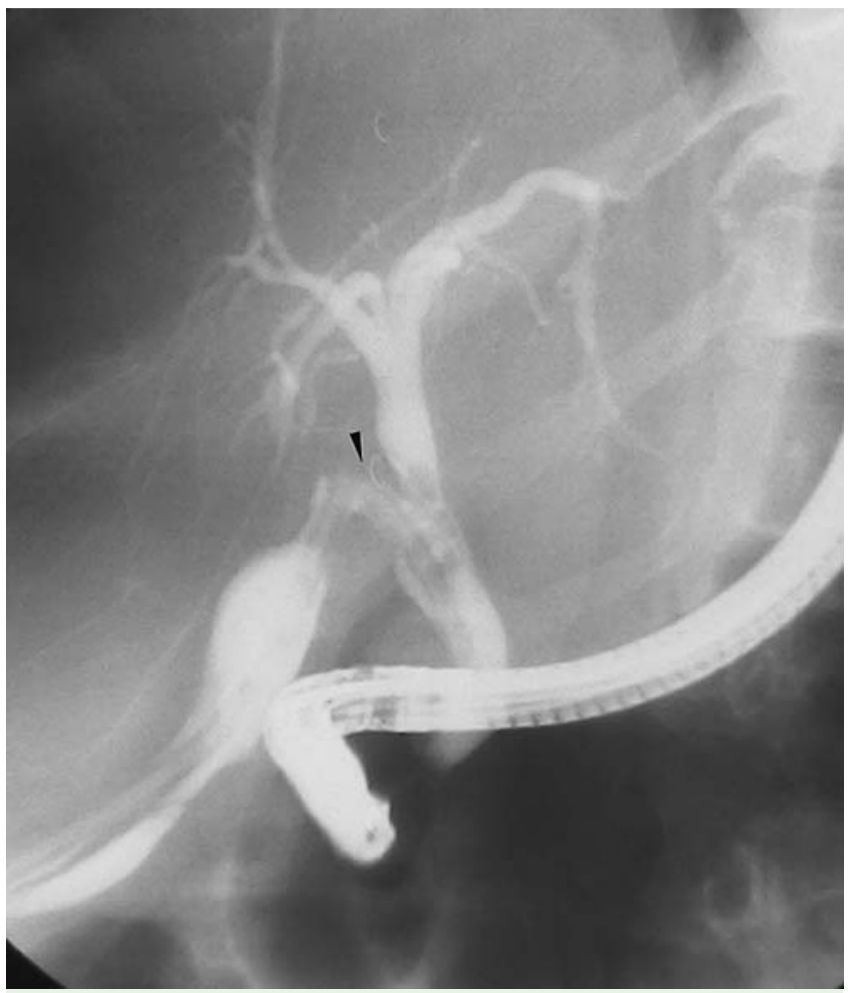

Fig. 6 Endoscopic retrograde cholangiopancreatography showing contrast leakage (arrowhead) around the T-tube (minor bile duct injury).

\section{Discussion \\ $\nabla$}

Biliary leak is common after cholecystectomy. Minor leaks can be detected by radioactive nuclear scanning in about $10 \%$ to $15 \%$ of patients, and most of them will be clinically insignificant. Significant post-cholecystectomy bile leaks occur in about $0.8 \%$ to $1.1 \%$ of patients $[12,13]$. Clinically detected leaks herald the presence of some sort of BDI [14].

In this study, we relied on the classification proposed in 1996 by Bergman et al. of the Amsterdam Academic Medical Center [5] because it is very helpful for categorizing leaks as minor or major and accurately reporting ERCP results. We considered RHD leak as a major BDI, despite its not being included in the original classification, in accordance with Hii et al. [8]. Also, we considered leakage at the site of choledochotomy after T-tube placement, not associated with stricture, to be a minor BDI.

Early in the 1990 s, bile leaks were usually managed conservatively; if no improvement was noted, laparotomy and abdominal drainage were performed. With the advent of minimally invasive techniques like ultrasound-guided percutaneous tube drainage and ERCP, the management protocol changed profoundly [15]. This change was even more evident as laparoscopic techniques progressed, especially intracorporeal suturing, which allowed the early control of bile leakage from slipped clips or minor bile duct injuries discovered in the early postoperative period [15]. In this study, we included only patients with proven, clinically significant bile leak who were referred to our endoscopy unit after either OC or LC. There were more OC patients than LC patients $(2: 1$ ratio). The ratio is similar to that in two large series reported from countries with similar economic circumstances $[7,16]$. This series included 17 patients whose index operations were performed at our institute. All except two operations were LCs; the first of these was open from the start for suspected gallbladder perforation, and the second was converted because of gallbladder empyema that obscured the biliary anatomy.

To our knowledge, this is the first study to compare OC and LC in a subset of patients to investigate differences in the underlying injuries. It is well known that the incidence of BDI has risen with the advent of LC. Many reports quote a BDI incidence for OC in the range of $0.1 \%$ to $0.2 \%$, whereas it has been in the range of $0.4 \%$ to $0.7 \%$ since the introduction of LC $[2,17,18]$. In this study, the nature of the BDIs differed significantly between the 


\begin{tabular}{|c|c|c|c|c|}
\hline Endoscopic treatment & Minor BDI $(n=78)$ & Major BDI $(n=30)$ & Failed ERCP $(n=3)$ & Total $(\%)(n=111)$ \\
\hline Primary management success rate, №. (\%) & $73(93.6 \%)$ & $16(53.3 \%)$ & 0 & $89(80.1 \%)$ \\
\hline \multicolumn{5}{|l|}{ Complications, No.(\%) } \\
\hline Persistent leak & $5(6.4 \%)$ & $2(6.6 \%)$ & & $7(6.3 \%)$ \\
\hline Mild pancreatitis & $2(2.6 \%)$ & $5(16.6 \%)$ & & $7(6.3 \%)$ \\
\hline Obstructed stent & $2(2.6 \%)$ & $2(6.6 \%)$ & & $4(3.6 \%)$ \\
\hline Missed diagnosis of CBD stones & $1(1.3 \%)$ & & & $1(0.9 \%)$ \\
\hline Cholangitis & $1(1.3 \%)$ & & & $1(0.9 \%)$ \\
\hline Sepsis/mortality & $1(1.3 \%)$ & & $1(33.3 \%)$ & $2(1.8 \%)$ \\
\hline \multicolumn{5}{|l|}{ Duration until resolution of leak, days } \\
\hline Mean (SD) & $3.7(1.2)$ & $5.4(3.1)^{1}$ & & \\
\hline Median (range) & $4(2-7)$ & $4(3-15)$ & & \\
\hline \multicolumn{5}{|l|}{ Secondary management procedures } \\
\hline Endoscopic & 4 & $1^{2}$ & & \\
\hline Surgical & 1 & 1 & & \\
\hline Overall endoscopic success rate, No. (\%) & 77 (98.7\%) & $16(53.3 \%)^{3}$ & & $93(83.7 \%)$ \\
\hline \multicolumn{5}{|l|}{ Number of ERCP sessions required } \\
\hline Mean (SD) & $1.9(0.7)$ & $2.4(1)$ & & \\
\hline Median (range) & $2(1-4)$ & $2(1-4)$ & & \\
\hline \multicolumn{5}{|l|}{ Definitive management procedures } \\
\hline Endoscopic & 6 & & & \\
\hline Surgical & 2 & 17 & & \\
\hline
\end{tabular}

ERCP, endoscopic retrograde cholangiopancreatography; BDI, bile duct injury.

${ }^{1} P=0.012$.

2 Failed to control bile leak.

${ }^{3} P<0.0001$.

groups. We can state that persistent bile leakage after $\mathrm{OC}$ is much more dangerous, with a high possibility of underlying major BDI $(P=0.001)$.

In the current study, the median time interval from surgery to ERCP was significantly shorter for the LC group (5 days), which is similar to the time in many reports on biliary leakage following LC $[3,19]$. In series in which most of procedures are OCs, this time interval is much longer and also similar to our result $[7,16]$. It reflects the low threshold for tolerating bile leakage following LC, leading to early referral.

The management of post-cholecystectomy injuries in our center is based on a multidisciplinary team approach. Broadly, the steps for management are (1) drainage of significant bilomas, (2) evaluation of the biliary anatomy, and (3) a decision to have the patient undergo endoscopic treatment or surgical treatment. The choice of endoscopic or surgical treatment usually depends on the nature and extent of the injury. Endoscopic treatment has almost replaced surgery for minor BDIs, such as cystic duct leaks and mild biliary strictures [20].

Before ERCP, imaging studies detected collections in 55\% of patients, and ultrasound-guided tube drains were used in $35 \%$ of patients. Abdominal ultrasound was the initial investigation of choice. It is safe, and it accurately screens collections or ascites. During the period of this study, MRCP was increasingly used to evaluate the biliary tree after abdominal ultrasound and before ERCP. The main reasons are the noninvasive nature of MRCP and its diagnostic accuracy [21]. ERCP is reserved for patients with preserved biliary tree continuity.

As in many other studies, cystic duct leak was the most common cause of post-cholecystectomy biliary leakage, accounting for about $60 \%$ of cases $[3,7,14,19]$. Cystic duct leaks can result from slipped clips or ligatures, thermal injuries proximal to clips, or blowout (e.g., because of missed CBD stones) [14]. Major BDI was identified in $28 \%$ of patients, which is less than the rate of more than $40 \%$ recently reported by Singh et al. [22]. They described their experience of 85 cases with post-cholecystectomy biliary leakage and found that $37.6 \%$ of patients had a ligated CBD and $7.5 \%$ had a middle CBD stricture. Their study did not compare patients who underwent OC (61\%) with those who underwent LC (39\%). Such a comparison in the current study showed an increased incidence of major BDI among patients undergoing $\mathrm{OC}$ and presenting with postoperative bile leakage. We cannot state a clear cause for this result; however, it may be explained by looking the other way around. Minor leaks are much less common with $\mathrm{OC}$, in which ligatures or even sutures are easily taken to control difficult cystic ducts.

The success rate of endoscopic therapy in controlling bile leak is reported to be in the range of $66 \%$ to $100 \%$. Different techniques are described in the literature, including endoscopic sphincterotomy, stent placement, and nasobiliary drains. Endoscopic sphincterotomy has a higher complication rate, while nasobiliary drains are poorly tolerated by patients [14]. Early in our experience, endoscopic sphincterotomy in two patients with cystic duct leaks and no missed stones did not result in rapid control of the leak, so stenting became our first option. Patients with missed stones were managed with endoscopic sphincterotomy and stone extraction alone if the leak appeared minimal, or with a combination of endoscopic sphincterotomy, stone extraction, and stent placement if the leak appeared to be significant during cholangiography or if the patient's condition required rapid control of the leak. Our routine practice is to place 10-Fr stents, bypassing the site of the leak if possible. With this approach, we have reached a success rate of $97 \%$.

According to the results of this series, we would suggest MRCP early in the course of managing bile leakage or suspected BDIs, especially following OC or converted LC. We think it should precede ERCP, which is invasive, may be complicated, or prove useless. Endoscopic therapy is successful in the majority of patients 
with minor BDIs and has accepted success rates in major BDIs with the exception of complete cutoff or tight strictures, for which surgery is the best treatment.

\section{Competing interests: None}

\section{References}

1 Fathy 0 , Wahab MA, Hamdy E et al. Post-cholecystectomy biliary injuries: one center experience. Hepatogastroenterology 2011; 58: 719724

2 Lau WY, Lai EC. Classification of iatrogenic bile duct injury. Hepatobiliary Pancreat Dis Int 2007; 6: 459-463

3 Ryan ME, Geenen JE, Lehman GA et al. Endoscopic intervention for biliary leaks after laparoscopic cholecystectomy: a multicenter review. Gastrointest Endosc 1998; 47: 261 - 266

4 Strasberg SM, Hertl M, Soper NJ. An analysis of the problem of biliary injury during laparoscopic cholecystectomy. J Am Coll Surg 1995; 180: $101-125$

5 Bergman JJ, van den Brink GR, Rauws EA et al. Treatment of bile duct lesions after laparoscopic cholecystectomy. Gut 1996; 38: 141 -147

6 Neuhaus P, Schmidt SC, Hintze RE et al. Classification and treatment of bile duct injuries after laparoscopic cholecystectomy [in German]. Chirurg 2000; 71: 166-173

7 Singh V, Singh G, Verma GR et al. Endoscopic management of postcholecystectomy biliary leakage. Hepatobiliary Pancreat Dis Int 2010; 9: 409-413

8 Hii MW, Gyorki DE, Sakata K et al. Endoscopic management of postcholecystectomy biliary fistula. HPB (Oxford) 2011; 13: 699-705

9 Fatima J, Barton JG, Grotz TE et al. Is there a role for endoscopic therapy as a definitive treatment for post-laparoscopic bile duct injuries? J Am Coll Surg 2010; 211: $495-502$

10 Murr MM, Gigot JF, Nagorney DM et al. Long-term results of biliary reconstruction after laparoscopic bile duct injuries. Arch Surg 1999; 134: 604-609; discussion 609-610
11 Lubikowski J, Post M, Bialek A et al. Surgical management and outcome of bile duct injuries following cholecystectomy: a single-center experience. Langenbecks Arch Surg 2011; 396: 699-707

12 Trondsen E, Ruud TE, Nilsen BH et al. Complications during the introduction of laparoscopic cholecystectomy in Norway. A prospective multicentre study in seven hospitals. Eur J Surg 1994; 160: 145-151

13 Barkun AN, Rezieg M, Mehta SN et al. Postcholecystectomy biliary leaks in the laparoscopic era: risk factors, presentation, and management. McGill Gallstone Treatment Group. Gastrointest Endosc 1997; 45: $277-282$

14 Rauws EA, Gouma DJ. Endoscopic and surgical management of bile duct injury after laparoscopic cholecystectomy. Best Pract Res Clin Gastroenterol 2004; 18: 829-846

15 Ahmad F, Saunders RN, Lloyd GM et al. An algorithm for the management of bile leak following laparoscopic cholecystectomy. Ann R Coll Surg Engl 2007; 89: 51 - 56

16 Ghazanfar S, Qureshi S, Leghari A et al. Endoscopic management of postoperative bile duct injuries. J Pak Med Assoc 2012; 62: 257-262

17 Adamsen S, Hansen $\mathrm{OH}$, Funch-Jensen $P$ et al. Bile duct injury during laparoscopic cholecystectomy: a prospective nationwide series. J Am Coll Surg 1997; 184: 571-578

18 Flum DR, Cheadle A, Prela C et al. Bile duct injury during cholecystectomy and survival in medicare beneficiaries. JAMA 2003; 290: 2168 2173

19 Kaffes AJ, Hourigan L, De Luca $N$ et al. Impact of endoscopic intervention in 100 patients with suspected postcholecystectomy bile leak. Gastrointest Endosc 2005; 61: 269-275

20 Karvonen J, Gullichsen R, Laine $S$ et al. Bile duct injuries during laparoscopic cholecystectomy: primary and long-term results from a single institution. Surg Endosc 2007; 21: 1069-1073

21 Khalid TR, Casillas VJ, Montalvo BM et al. Using MR cholangiopancreatography to evaluate iatrogenic bile duct injury. AJR Am J Roentgenol 2001; 177: 1347-1352

22 Singh VK, Khashab MA, Okolo PI3rd et al. ERCP or laparoscopic exploration for the treatment of suspected choledocholithiasis? Arch Surg 2010; 145: 796; author reply 796 